\title{
Time factor in the measurement of response to bronchodilators
}

\author{
G. J . M USH IN \\ From Prince Henry's Hospital, Melbourne, Australia
}

\begin{abstract}
The measurement of response to bronchodilators by recording the change in forced expiratory volume in 1 second (F.E.V.1.0 $)$ can underestimate response unless the correct time for postbronchodilator tests is chosen. In 18 patients given isoprenaline, the time of peak response varied, but a 30-minute testing time gave the closest approximation to peak response. In order to test whether repeated doses would increase the response, inhalations of isoprenaline were given at 30-minute intervals, the F.E.V $\cdot_{1 \cdot 0}$ being measured after each dose. There was a further response after successive doses until a plateau was reached, usually after the third dose. The maximum response obtained was often considerably greater than the response after the first administration of isoprenaline, the average increase in F.E.V $\cdot_{1 \cdot 0}$ being $600 \mathrm{ml}$. after the first dose and $840 \mathrm{ml}$. after repeated doses. A similar response was obtained in four patients using orciprenaline spray administered with a metered aerosol, the dose being repeated at hourly intervals. Four patients were given repeated inhalations of isoprenaline until the response reached a plateau, and then $250 \mathrm{mg}$. of aminophylline was injected intravenously. None of these patients showed any further improvement with aminophylline. The significance of these findings is discussed.
\end{abstract}

Response to bronchodilators is commonly tested by the measurement of forced expiratory volume in one second (F.E.V..$_{1.0}$ ) before and after a dose of a sympathomimetic drug, frequently given in aerosol form. The information obtained is used both qualitatively and quantitatively in the assessment of reversibility of airways obstruction. It is also used as a method of studying the actions of various drugs.

In order to provide reliable and reproducible quantitative information the drug should be given, and the F.E.V..$_{1 \cdot 0}$ recorded, in a manner which will give a maximum response. Anything short of this will cause variations, depending on what proportion of the maximum response is obtained. The superiority of the augmented histamine test of gastric secretion (Kay, 1953) over the standard histamine test is an analogous situation.

There is evidence that the dose of isoprenaline inhalation required for maximal effect is small (Altounyan, 1964). Altounyan found that five inhalations of a $1.0 \%$ solution of isoprenaline from a Wright nebulizer $(0.37 \mathrm{mg}$.), or four doses from a pressurized multidose inhaler $(0.3 \mathrm{mg}$.), were above the amount needed for maximal response.

However, it seemed that two other factors could affect the magnitude of the response obtained.
1. The time at which the post-bronchodilator test is performed: Edwards (1964), Kennedy and Thursby-Pelham (1964), El-Shaboury (1964), and Chamberlain, Muir, and Kennedy (1962) have shown that, after isoprenaline inhalation in suitable patients, there is a rapid improvement, which reaches a peak in 15 minutes and then declines slowly.

Other investigators have chosen a fixed time at which the post-bronchodilator test is performed, and this is sometimes within five minutes of the inhalation (Saunders, 1965; Feinmann and Newell, 1963). The shorter time is also frequently used in routine testing of patients. Because of the rapid decrease in airways obstruction up to 15 minutes after isoprenaline inhalation, and the possible variations in individual patients, the selection of a fixed time for post-bronchodilator testing, especially if it is shorter than 15 minutes, may underestimate the greatest response.

2. Effect of repeated doses: Kennedy and Thursby-Pelham (1964) noted that three and a half hours after the administration of various bronchodilators an inhalation of aerosol adrenaline would produce a reading which was greater than that achieved in the preceding three and a half hours. Capel (1959) described the beneficial effect of a second inhalation of adrenaline spray, 
after the maximum response from the first dose had been achieved. It seemed possible, therefore, that repeated doses of a bronchodilator might produce repeated augmentation of response until a plateau of maximum response was achieved.

This study was performed in order to investigate these two points.

\section{MATERIAL AND METHODS}

The only criterion used for selecting patients to attend for this study was that on previous testing there had been a $25 \%$ or greater increase in F.E.V.1.0 $5 \mathrm{~min}$. after administration of a $1 \%$ isoprenaline aerosol, and that on the preliminary test the post-bronchodilator F.E.V.1.0: vital capacity (V.C.) ratio was less than $70 \%$. These patients were regarded as having airways obstruction which was partly, but not completely, reversed $5 \mathrm{~min}$. after a single dose of bronchodilator. It was found that on the days of the study a number of the patients had changed from their previous state ; some had become worse and were too ill to test ; but, more frequently, they had improved to the extent that there remained only a small degree of airways obstruction. The study was not continued on these patients. Twenty-two patients were studied, nine women and 13 men. Their ages ranged between 26 and 63 years, with an average of 47 years. They all attended in the morning, having taken no bronchodilator since the previous evening-unless they had become distressed. Steroid therapy, if being used, was not altered.

Pre-bronchodilator F.E.V.1.0 and V.C. were measured with a 9-litre Godart spirometer, taking three measurements of each, or more if these were not considered satisfactory. Eighteen of the patients were then given $3 \mathrm{~min}$. inhalation of a $1 \%$ solution of isoprenaline sulphate from a Wright nebulizer driven by an oxygen cylinder at approximately 6 litres per minute. F.E.V.1.0 measurements were repeated at 5,15 , and 30 minutes, two satisfactory readings being taken each time. A second 2-min. inhalation was then given, and further measurements were taken at 5, 15, and 30 minutes, the cycle being repeated until three or four doses had been given. During performance of the F.E.V.1.0 the forced expiration was stopped at about 2 sec. to prevent coughing which can occur on complete expiration.

Similar studies were performed on another four patients using orciprenaline (Alupent), two inhalations $(2 \mathrm{mg}$.) from the metered aerosol being given. F.E.V.1.0 was measured at $5,15,30$, and 60 minutes before repeating the cycle. The highest F.E.V.1.0 recordings were used in the results.

\section{RESULTS}

TIME AFTER A SINGLE ADMINISTRATION OF BRONCHODILATOR AT WHICH THE RESPONSE IS MEASURED After the first dose of isoprenaline, three of the 18 patients had their greatest response in $5 \mathrm{~min}$., four in $15 \mathrm{~min}$., and eight in $30 \mathrm{~min}$. One patient had equal greatest responses at 5 and $30 \mathrm{~min}$. and two at 15 and $30 \mathrm{~min}$. Testing at $5 \mathrm{~min}$. after bronchodilator gave the highest response in only four of 18 patients. At $15 \mathrm{~min}$. six and at $30 \mathrm{~min} .13$ of the 18 patients showed the most improvement. With orciprenaline one patient had the greatest response at $30 \mathrm{~min}$., and three at 60 minutes.

If response is expressed as change in F.E.V. $\cdot_{1_{1} \cdot 0}$ from the original reading $\left(\Delta \mathrm{F}\right.$.E. $\left.\mathrm{V}_{\left.\cdot_{1} \cdot{ }_{0}\right)}\right)$ the average response of the patients given isoprenaline was $460 \mathrm{ml}$. after $5 \mathrm{~min}$., $520 \mathrm{ml}$. after $15 \mathrm{~min}$., and $560 \mathrm{ml}$. after 30 minutes. The average of the maximum response obtained at any of these times was $600 \mathrm{ml}$.

Some workers express response to bronchodilator as percentage improvement of the F.E.V. ${ }_{1} \cdot{ }_{0}$ measured before treatment. The validity of this method of analysis has been challenged by Feinmann and Newell (1963). However, the results expressed in this way are shown in the Table.

\section{T A B L E}

\begin{tabular}{|c|c|c|c|c|c|}
\hline \multirow[t]{3}{*}{ RESPONSE OF 18} & $\mathbf{P A}$ & is & $E \mathbf{K}$ & & \\
\hline & \multicolumn{4}{|c|}{ Time after First Dose } & \multirow{2}{*}{$\begin{array}{c}\text { Maximum } \\
\text { after } \\
\text { Repeated } \\
\text { Doses }\end{array}$} \\
\hline & $\stackrel{5}{\min .}$ & $\begin{array}{c}15 \\
\text { min. }\end{array}$ & $\begin{array}{c}30 \\
\text { min. }\end{array}$ & $\begin{array}{l}\text { Maxi- } \\
\text { mum }\end{array}$ & \\
\hline $\begin{array}{cc}\text { Average } & \Delta \text { F.E.V.1.0 } \\
(\mathrm{ml} .) & \ldots\end{array}$ & 460 & 520 & 560 & 600 & 840 \\
\hline $\begin{array}{ccc}\text { Average } & \% & \text { improve- } \\
\text { ment } & \ldots & .\end{array}$ & 30 & 36 & 38 & 40 & 63 \\
\hline
\end{tabular}

Average initial F.E.V.1·0 $=1,500 \mathrm{ml}$.

It is apparent from these data, and from inspection of the results of individual patients, that measuring the F.E.V.V $\cdot_{1 \cdot 0} 5 \mathrm{~min}$. after isoprenaline inhalation can appreciably underestimate the response. Testing at a series of times gives the best information, but if, for convenience, a fixed time is chosen, the 30 -min. interval is the optimum one.

RESPONSE AFTER REPEATED DOSES Figure 1 shows the maximum change in F.E.V..$_{1 \cdot 0}$ from the pretreatment level following successive doses of bronchodilator. The pattern is one of a stepwise increase in F.E.V..$_{1 \cdot 0}$ until a plateau is reached, usually after the third dose.

The maximum increase in F.E.V. $\cdot_{1 \cdot 0}$ of the 18 patients given isoprenaline rose from $600 \mathrm{ml}$. after the first dose to $840 \mathrm{ml}$. after repeated doses, 


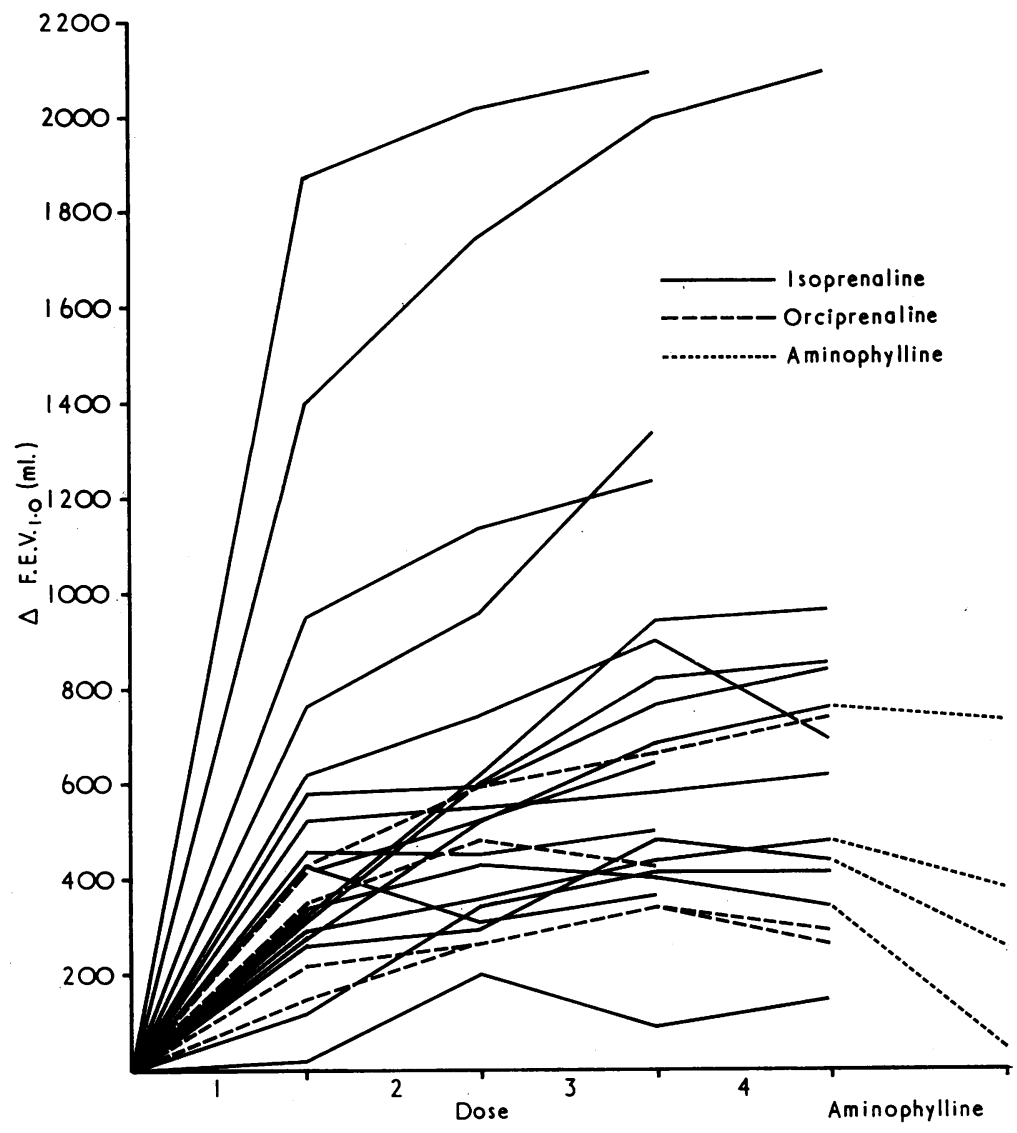

FIG. 1. The maximum change in F.E.V.1.0 from pre-treatment values, after successive doses of bronchodilator.

representing percentage improvement figures of $40 \%$ and $63 \%$ respectively. A similar pattern is seen in the patients given orciprenaline.

Figure 2 shows the actual F.E.V. $\cdot_{1 \cdot 0}$ both before bronchodilator and at the time of the greatest rise after each dose. There was no correlation between the original level and the response nor between the response after the first dose compared to responses after subsequent doses. Only one patient showed a maximum response after the first inhalation of bronchodilator.

It was noted that, although after the first dose the maximum response tended to occur at $30 \mathrm{~min}$., the maximum responses after repeated doses were earlier, the 15 -min. interval tending to give the highest reading. After repeated doses, the 5-min. reading was still lower than the 15 -min. record.

Four patients were given $250 \mathrm{mg}$. aminophylline by slow intravenous injection after the maximum response from four inhalations of isoprenaline had been achieved. Figures 1 and 2 show some decrease in F.E.V $_{\cdot 1 \cdot 0}$ in all of these, F.E.V.1.0 having been measured over a further 30-min. period.

SIDE-EFFECTS Some of the patients experienced palpitations, and this was more common after the first and largest dose of isoprenaline. There was often some tachycardia after isoprenaline, and one patient developed a pulse rate of 140 per minute. This occurred after the second dose of isoprenaline, and subsequent inhalations in this patient were limited to half a minute. One patient who had four inhalations of orciprenaline was given a 3-min. inhalation of $1 \%$ isoprenaline one hour later. She developed some extrasystoles which settled after 2 minutes. One patient felt faint during an intravenous injection of aminophylline and had a transient bradycardia with a systolic blood pressure of $60 \mathrm{~mm}$. Hg. This episode was considered to be vaso-vagal rather than a direct effect of aminophylline. 


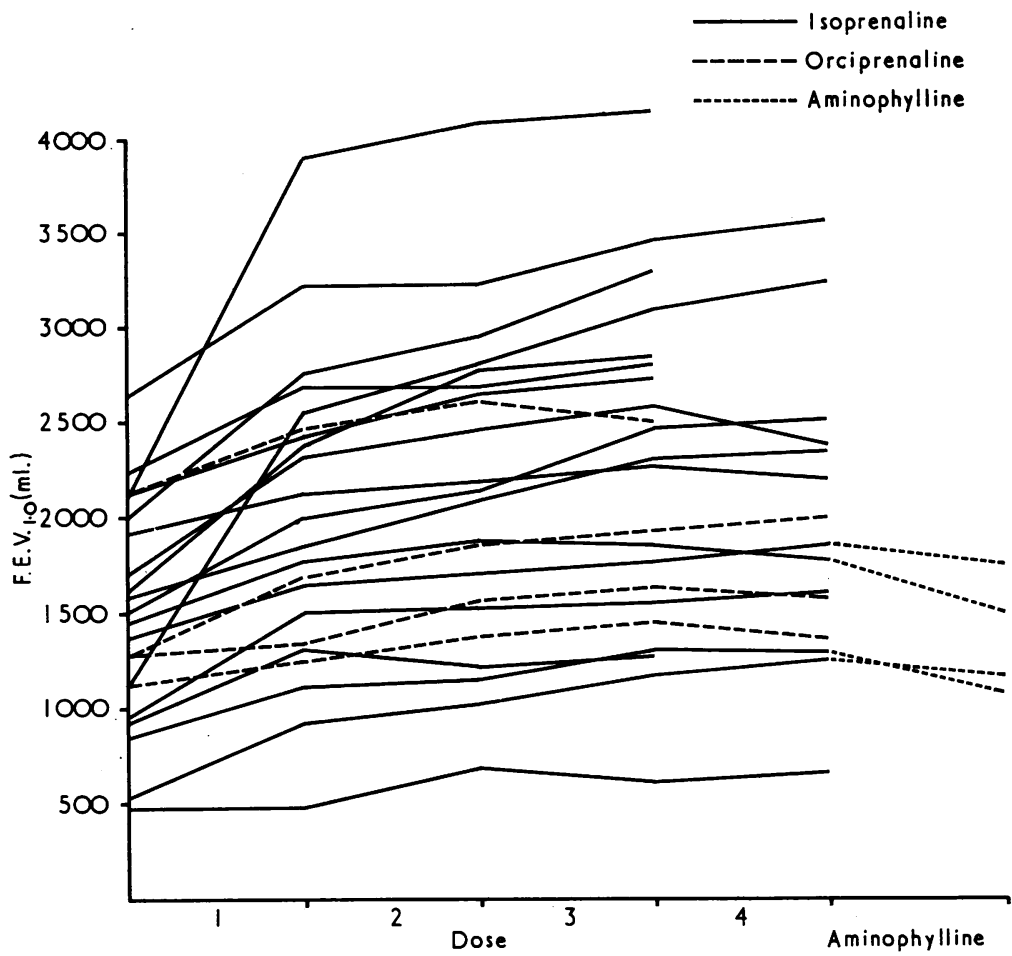

FIG. 2. The F.E.V. ${ }_{1 \cdot 0}$ before testing and after successive doses of bronchodilator.

\section{DISCUSSION}

When a patient with reversible airways obstruction is given an inhalation of a bronchodilator drug there is an increase in F.E.V.1.0 a period of up to 15 or $30 \mathrm{~min}$., with a slower decrease back to the pre-treatment state. This time-response curve varies with different drugs, but the general feature of a more rapid increase than decline of the curve is important in the selection of the time to perform the post-bronchodilator test, if a value as near as possible to the peak is required. Testing before the peak occurs can appreciably underestimate response. Repeated testing to find the time of greatest response gives the highest values, but if a fixed time is chosen, one shortly after the peak is open to less error because of the comparatively slow decline in the curve. Isoprenaline inhalation is commonly used for testing response, and this study suggests that, if a fixed time for post-bronchodilator testing is chosen, the 30-min. interval gives values closest to the peak, the 5-min. interval giving an appreciably lower response. With longer-acting bronchodilator drugs, such as orciprenaline (Edwards, 1964 ; Woolcock, Tai, and Pain, 1964) and a combination of isoprenaline with atropine methonitrate (Kennedy and Thursby-Pelham, 1964), it seems that a longer time of $60 \mathrm{~min}$. would be preferable for testing. Because the decline in action of these drugs is prolonged, they present the advantage that the peak effect is less likely to be missed.

The augmentation effect of repeated doses of bronchodilator gives a final improvement considerably greater than that after the first dose. An explanation suggested by Capel (1959) is that each dose permits further penetration of subsequent inhalations. Two patients were given repeated doses of $20 \mathrm{mg}$. isoprenaline sulphate sublingually. It was thought that by giving the dose systemically this factor of increasing penetration would be avoided. Both patients showed an increased response after the second dose. This does not disprove this explanation, because it is possible that the poorly ventilated areas are also poorly perfused, and that the increasing penetration here occurs on the vascular side. Another factor is that $20 \mathrm{mg}$. isoprenaline sublingually may not be a maximal dose, this being difficult to increase further because of the circulatory effects. 
Another explanation for the response to repeated doses of bronchodilator depends upon the variation in response in an individual patient with the initial degree of airways obstruction. Hume and Gandevia (1957) described a 'response curve' in patients with asthma, where, during a severe episode, there is little improvement following isoprenaline, the response increasing as the patient improves and finally diminishing again as a state free of airways obstruction is approached. Pain and Read (1963) showed that the response depends not only on the original F.E.V. $\cdot_{1 \cdot{ }_{0}}$ but on whether the patient is improving or deteriorating at the time. With repeated doses, as in this study, the basic state is altered by each dose, and the patient may be regarded as having a lesser degree of obstruction with successive doses, and therefore being capable of further response.

The ability to show this augmentation of response may continue for at least some hours. One patient was given three inhalations of isoprenaline at half-hourly intervals and then another after a further three and a half hours. The final F.E.V..$_{1 \cdot 0}$ was the highest obtained.

A therapeutic implication could be to instruct patients who are beginning treatment with bronchodilator by inhalation to repeat the inhalation for three doses at intervals, depending on the time of duration of action of the drug. For isoprenaline inhalation this may be halfhourly and for orciprenaline hourly. After this, less frequent administrations may maintain or perhaps augment the improvement.

Studies in which quantitative measurements of response to bronchodilator are used may reach unjustifiable conclusions if the augmentation effect is not recognized. For example, Hume and Jones (1961) advocated the use of a combination of bronchodilator drugs which differ in their site of action, e.g., a sympathomimetic drug such as isoprenaline followed by aminophylline. The evidence for this is that after a response to isoprenaline is obtained, a further improvement can be achieved with intravenous aminophylline. It is possible that it was not the different action of aminophylline but rather the augmentation of a further dose of bronchodilator which produced the improvement. This is supported by the failure of response to aminophylline of the four patients described here who had already been given repeated doses of isoprenaline.

I am grateful to the physicians of Prince Henry's Hospital for allowing me to carry out these tests on their patients. This study was supported by a grantin-aid from the Asthma Foundation of Victoria.

\section{REFERENCES}

Altounyan, R. E. C. (1964). Variation of drug action on airway obstruction in man. Thorax, 19, 406.

Capel, L. H. (1959). Inhalation therapy and apparatus. In Bronchial Asthma: a Symposium, p. 43. Chest and Heart Association, London.

Chamberlain, D. A., Muir, D. C. F., and Kennedy, K. P. (1962). Atropine methonitrate and isoprenaline in bronchial asthma. Lancet, 2, 1019.

Edwards, G. (1964). Orciprenaline in treatment of airways obstruction in chronic bronchitis. Brit. med. J., 1, 1015.

El-Shaboury, A. H. (1964) Controlled study of a new inhalant in asthma and bronchitis. Ibid., 2, 1037.

Feinmann, L., and Newell, D. J. (1963). Isoprenaline in the treatment of chronic bronchitis. Brit. J. Dis. Chest, 57, 140.

Hume, K. M and Gandevia, B. (1957). Forced expiratory volume before and after isoprenaline. Thorax, 12, 276.

- and Jones, E. Rhys (1961). The response to bronchodilators in intrinsic asthma. Quart. J. Med., 30, 189.

Kay, A. W. (1953). Effect of large doses of histamine on gastric secretion of $\mathrm{HCl}$. Brit. med. J., 2, 77.

Kennedy, M. C. S., and Thursby-Pelham, D. C. (1964). Some adrenergic drugs and atropine methonitrate given by inhalation for asthma: a comparative study. Ibid., 1, 1018.

Pain, M. C. F., and Read, J. (1963). Patterns of response to bronchodilator in young patients with astbma. Aust. Ann. Med., 12, 216.

Saunders, K. B (1965). Misuse of inhaled bronchodilator agents. Brit, med. J., 1, 1037.

Woolcock, A. J., Tai, E. H., and Pain, M. C. F. (1964). A ssessment of orciprenaline ("Alupent"), a long-acting bronchodilator. Med. J. Aust., 2, 89. 